\title{
Modelling Population-Level Drug Use with Demographic and Geographic Approaches and Techniques
}

Fanny Janssen ${ }^{1,2}$ and Eelko Hak ${ }^{2,3}$

${ }^{1}$ Population Research Centre, Faculty of Spatial Sciences, University of Groningen, The Netherlands

${ }^{2}$ Department of Pharmacy, Unit Pharmacoepidemiology and Pharmacoeconomics, University of Groningen, The Netherlands

${ }^{3}$ Department of Epidemiology, University Medical Center Groningen, University of Groningen, The Netherlands

\section{The Importance of Modelling Population-Level Drug Use}

Within the field of pharmacoepidemiology and drug safety as in the wider field of epidemiology focus has been on individual-level studies. However, the impact of drug use for the society as a whole cannot directly be inferred from such studies and population-level causal designs are required. For example, for health policy it is crucial to know the role of drugs in affecting regional, national or international morbidity and mortality trends. Similarly, predicting (future) levels of local health care and drug use is essential for prevention purposes, targeted allocation of care and meeting health demands. Moreover, actual end users of drugs in society may largely differ from clinical trial populations $[1,2]$ used to study the efficacy of drugs for registration purposes [3].

\section{Demography and Geography}

The causal and predictive modelling of population-level drug use requires approaches and techniques from the scientific fields of (medical) demography and geography.

Demography-in its traditional form-can be labeled as "the statistical study of populations" [4], and is mainly concerned with the study of changes in size, composition and distribution of populations. Three processes are distinguished: fertility, mortality and migration. Nowadays, focus is as well on the implications for individuals and societies of demographic processes at the population level (e.g. population ageing) and on macro consequences of (changes in) individual demographic behavior (e.g. health behavior). Medical demography focusses on mortality/disease processes behind changes in population size and structure, and has clear links with epidemiology [5].

Geography mainly focusses on spatial patterns and on the organization of people across space and in relationship with their environment [6]. Medical geography, acknowledged as a sub-discipline in geography since the 1950s, is the branch in geography that uses "the tools and approaches of geography to tackle health-related questions" including health care [7]. These geographical techniques include mapping, location analysis, spatial analysis, but also more qualitative approaches. In this short commentary we focus in particular on the added value of spatial analysis, which can be defined as 'the quantitative study of phenomena that are located in space' [8].

\section{Added Value of Demographic Approaches and Techniques}

In the article by Babor (1994) [9] on the connections between demography, epidemiology and psychopharmacology, the two standard ways of including traditional demography into (pharmaco) epidemiological studies are presented. These are (i) the inclusion of demographic variables (sex, age, ethnicity, marital status, socioeconomic status, etc.) for an understanding of medicine use and (ii) the study of medicine use in relation to population dynamics, e.g. divorce rate, migration patterns, urbanization etc. Additional demographic approaches and techniques that are relevant for pharmacoepidemiology include adequate control for differences in compositional factors (e.g. age-standardisation) when assessing trends in medicine use and effectiveness of drugs at the population-level, life table techniques, ageperiod-cohort analyses and future health projections.

In the research line "Applying demographic and geographic techniques to medicine use", at the unit of Pharmacoepidemiology \& Pharmacoeconomics at the University of Groningen until now focus has been on the added value of age-period-cohort analyses. Ageperiod-cohort analyses recently, have received renewed attention in the field of Demography [10].

In age-period-cohort analyses [11-13], simultaneous control for effects of age, period (calendar time) and cohort is pursued. Cohort effects relate to a group of individuals who share formative experiences and other events; birth cohorts are being studied most often. Birth cohort effects have been observed for many causes of death $[14,15]$. Within pharmacoepidemiology, birth cohort effects have been hypothesized to explain the inability to demonstrate the effectiveness of influenza vaccination in population-level studies [16,17]: e.g. some cohorts will have experienced previous influenza epidemics and developed immunity. Another likely mechanism is that cohorts, because of their different cultural and moral climate, have different therapy adherence. Especially for population-level drug utilization studies, ignoring differences between birth cohorts might lead to biased outcomes.

Within our research group, we demonstrated the importance of cohort effects in the description and explanation of drug use, e.g. for statin therapy [18] and in effect studies of guideline changes, e.g. for benzodiazepine drugs [19]. Furthermore, it was observed that birth cohort effects confound population-level effect estimates of guideline changes on prevalence of statin use in patients with diabetes [20]. It seemed however that-using merely aggregate data-cohort effects do not appear to modify effects of statin therapy on cardiovascular mortality at the population-level [21].

*Corresponding author: Fanny Janssen, Assistant Professor, Population Research Centre (PRC), Faculty of Spatial Sciences, University of Groningen, The Netherlands, Tel: +31-50-363-4421; E-mail: f.janssen@rug.nl

Received May 21, 2014; Accepted June 28, 2014; Published June 30, 2014

Citation: Janssen F, Hak E (2014) Modelling Population-Level Drug Use with Demographic and Geographic Approaches and Techniques. Adv Pharmacoepidemiol Drug Saf 3: 158. doi:10.4172/2167-1052.1000158

Copyright: (c) 2014 Janssen F, et al. This is an open-access article distributed under the terms of the Creative Commons Attribution License, which permits unrestricted use, distribution, and reproduction in any medium, provided the original author and source are credited. 


\section{Added Value of Using Geographic Approaches and Techniques}

Our recent review on the use of spatial analysis in pharmacoepidemiology [22] showed that a geographic approach is only applied in a minority of studies, and also with less advanced methods as compared with such studies in the broader field of general epidemiology. From our study and the previous reviews of the use of spatial analysis in the broader epidemiological field [23-30] the added value of the use of spatial analysis, however, was clearly shown.

Geographic approaches and techniques can not only aid the description of geographic patterns in health and drug use, or the explanation or prediction of the occurrence of disease (clusters) in certain areas, but it can also identify missed diagnoses or undertreatment in certain areas as indicated by differences between medicine use and the health situation in these areas. In doing so, important local factors such as health care access, socioeconomic status and demographic composition can and need to be integrated. With this knowledge, areas at risk and in need for health interventions can be localized and targeted.

Within our group, for example, we identified risk populations for type II diabetes mellitus through the examination of local differences in drug use by means of spatial techniques (clustering, geographically weighted regression, assessing regional effect modification, checking for spatial lag and spatial error), resulting in a prediction model [31,32]. The prediction model included deprivation, the share of elderly population, population ageing and population growth, and was able to predict high or low five-year prevalence of oral antidiabetics use for those aged 45 and over in the period 2005-2009 by four-digit postal codes in the Northern Netherlands with an area under the receiver operating curve as high as 0.88 [33].

Next to the application of geographically weighted regression, in which spatial differences in the observed relations can be assessed and considered, a spatio-temporal analysis may be very relevant as well. Adding the time dimension through spatio-temporal analysis can reveal whether the observed relationships and the spatial differences therein are stable over time and whether an autonomous temporal trend exists that needs to be taken into account. For this purpose spatial panel modeling [34,35] can be applied, i.e. a specific type of multi-level modelling with spatial unit and time as the distinct levels [36] for an application of spatio-temporal analysis in the general field of epidemiology.

\section{To Conclude}

Although the application of both demographic and geographic approaches within the pharmacoepidemiological field is still limited, its added value for modeling population-level drug use is clear. We strongly recommend the uptake of demographic and geographic approaches to enrich pharmacoepidemiological research.

\section{References}

1. Martin K, Begaud B, Latry P, Miremont-Salame G, Fourrier A, et al. (2004) Differences between clinical trials and post-marketing use. $\mathrm{Br} \mathrm{J}$ Clin Pharmaco 57: 86-92.

2. Critchley JA, Capewell S (2002) Why model coronary heart disease? Eur Heart J 23: 110-116

3. Shepherd J, Blauw GJ, Murphy MB, Bollen EL, Buckley BM, et al (2002) Pravastatin in elderly individuals at risk of vascular disease (PROSPER): a randomised controlled trial. Lancet 360: 1623-1630.
4. Bonneux LG (2009) Medical demography and epidemiology: dizygotic twins. Eur J Epidemiol 24: 157-159.

5. Rockett IRH (1999) Population and Health: An introduction to epidemiology. Population Bulletin (Population Reference Bureau) 49: 1-47.

6. Moseley W, Lanegran D, Pandit K (2007). The Introductory Reader in Human Geography: Contemporary Debates and Classic Writings. Malden, MA Blackwell.

7. Anthamatten P, Hazen $\mathrm{H}$ (2011) An introduction to the geography of health Oxon Routledge.

8. Bailey TC, Gatrell AC (1995) Interactive spatial data analysis Essex Longman Scientific \& Technical.

9. Babor TF (1994) Overview: Demography, epidemiology and psychopharmacology-making sense of the connections. Addiction 89: 1391 1396.

10. Tolney S (2013) Editor's Note. Demographic Research 50: 1943-1944.

11. Clayton D, Schifflers E (1987) Models for temporal variation in cancer rates. II: Age-period-cohort models. Stat Med 6: 469-81.

12. Yang Y (2008) Trends in US adult chronic disease mortality, 1960-1999: age, period, and cohort variations. Demography 45: 387-416.

13. Carstensen B (2007) Age-period-cohort models for the Lexis diagram. Stat Med 26: $3018-3045$

14. Janssen F, Kunst AE (2005) Cohort patterns in mortality trends among the elderly in seven European countries, 1950-99. International Journal of Epidemiology 34: 1149-1159.

15. Amiri M, Kunst AE, Janssen F, Mackenbach JP (2006) Cohort-specific trends in stroke mortality in seven European countries were related to infant mortality rates. J Clin Epidemiol 59: 1295-302.

16. Simonsen L, Reichert TA, Viboud C, Blackwelder WC, Taylor RJ, et al. (2005) Impact of influenza vaccination on seasonal mortality in the US elderly population. Arch Intern Med 165: 265-272.

17. Rizzo C, Viboud C, Montomoli E, Simonsen L, Miller MA (2006) Influenzarelated mortality in the Italian elderly: no decline associated with increasing vaccination coverage. Vaccine 24 : 6468-6475.

18. Bijlsma MJ, Hak E, Bos JH, de Jong-van den Berg LT, Janssen F (2012) Inclusion of the birth cohort dimension improved description and explanation of trends in statin use. J Clin Epidemiol 65: 1052-1060.

19. Bijlsma MJ, Hak E, Bos J, De Jong-van den Berg LT, Janssen F (2013) Assessing the effect of a guideline change on drug use prevalence by including the birth cohort dimension: the case of benzodiazepines. Pharmacoepidemiol Drug Saf 22: 933-941.

20. Bijlsma MJ, Janssen F, Lub R, Bos HJ, De Vries, et al. (submitted) Birth cohort dimension confounds population-level effect estimates of guideline changes on prevalence of statin use in patients with diabetes.

21. Bijlsma MJ, Janssen F, Bos HJ, Kamphuizen PW, Vansteelandt S, et al (submitted) Association between statin use and cardiovascular mortality at the population-level in the Netherlands 1994-2010.

22. Dijkstra A, Hak E, Janssen F (2013) A systematic review of the application of spatial analysis in pharmacoepidemiologic research. Ann Epidemiol 23: 504514

23. Clarke KC, McLafferty SL, Tempalski BJ (1996) On epidemiology and geographic information systems: a review and discussion of future directions. Emerging infectious diseases 2: 85-92.

24. Moore DA, Carpenter TE (1999) Spatial analytical methods and geographic information systems: use in health research and epidemiology. Epidemiol Rev 21: $143-161$

25. Carpenter TE (2011) The spatial epidemiologic ( $r$ ) evolution: a look back in time and forward to the future. Spat Spatiotemporal Epidemiol 2: 119-124.

26. Rezaeian M, Dunn G, St Leger S, Appleby L (2007) Geographical epidemiology, spatial analysis and geographical information systems: a multidisciplinary glossary. J Epidemiol Community Health 61: 98-102.

27. Auchincloss AH, Gebreab SY, Mair C, Diez Roux AV (2012) A review of spatia methods in epidemiology, 2000-2010. Annual Review of Public Health 33: 107 122 
Citation: Janssen F, Hak E (2014) Modelling Population-Level Drug Use with Demographic and Geographic Approaches and Techniques. Adv Pharmacoepidemiol Drug Saf 3: 158. doi:10.4172/2167-1052.1000158

Page 3 of 3

28. Higgs G (2009) The role of GIS for health utilization studies: literature review. Health Services and Outcomes Research Methodology 9: 84-89.

29. Nykiforuk Cl, Flaman LM (2011) Geographic information systems (GIS) for Health Promotion and Public Health: a review. Health Promot Pract 12: 63-73.

30. Pfeiffer D, Robinson T, Stevenson M, Stevens KB, Rogers DJ, et al. (2008) Spatial analysis in epidemiology. New York Oxford University Press.

31. Dijkstra A, Janssen F, De Bakker M, Bos J, Lub R, et al. (2013) Using spatial analysis to predict health care use at the local level: a case study of type 2 diabetes medication use and its association with demographic change and socioeconomic status. PLoS One 8: e72730.

32. Dijkstra A, Janssen F, Bos HJ, van Wissen LJG, Hak E (submitted) Geographic consistency in the relation between local type 2 diabetes mellitus medication use and its predictors.
33. Dijkstra A, Janssen F, Bos HJ, van Wissen LJG, Hak E (ongoing) Predicting high oral antidiabetics medication use at local level.

34. Anselin L, Syabri I, Kho Y (2006) GeoDa: An introduction to spatial data analysis. Geographical Analysis 38: 5-22.

35. Elhorst JP (2003) Specification and estimation of spatial panel data models. International Regional Science Review 26: 244-268.

36. Loughnan M, Tapper N, Phan T (2014) Identifying vulnerable populations in sub-tropical Brisbane, Australia: A guide for heat wave preparedness and health promotion. ISRN Epidemiology 2014: 1-12. 